\title{
Endoscopic Retrograde Cholangiopancreatography in Post Gastrectomy Patients
}

\author{
Chang-Hwan Park \\ Department of Internal Medicine, Chonnam National University Medical School, Gwangju, Korea
}

Endoscopic retrograde cholangiopancreatography (ERCP) in post-gastrectomy patients with Billroth II (BII) reconstruction and Rouxen-Y (RY) reconstruction presents a challenge to therapeutic endoscopists. Major difficulties, including intubation to the ampulla of Vater, selective cannulation, and ampullary intervention, must be overcome in these patients. Recent data have shown that deviceassisted ERCP allows for high success rates in these patients because various devices are useful for overcoming major difficulties. Therefore, good knowledge of postoperative anatomy and various devices is mandatory before performing ERCP procedures for postgastrectomy patients. Clin Endosc 2016;49:506-509

Key Words: Cholangiopancreatography, endoscopic retrograde; Billroth II reconstruction; Roux-en-Y reconstruction

\section{INTRODUCTION}

Endoscopic retrograde cholangiopancreatography (ERCP) is currently a standard treatment for pancreatobiliary diseases. ${ }^{1}$ ERCP in post-gastrectomy patients with Billroth II (BII) reconstruction and Roux-en-Y (RY) reconstruction presents a challenge for pancreatobiliary endoscopists. Four major challenges were encountered when performing ERCP for post-gastrectomy patients: first, recognizing the afferent loop; second, reaching the ampulla of Vater; third, cannulating the ampulla of Vater; and fourth, performing the ampullary intervention. ${ }^{2}$ Therefore, good knowledge of postoperative anatomy and various devices including endoscopes and accessories are mandatory before performing ERCP procedures for post-gastrectomy patients. ${ }^{3}$ Some examples of post-gastrectomy anatomies include the Billroth I gastrectomy with gastro-

Received: August 22, 2016 Revised: October 3, 2016

Accepted: October 13, 2016

Correspondence: Chang-Hwan Park

Department of Internal Medicine, Chonnam National University Medical School, 42 Jebong-ro, Dong-gu, Gwangju 61469, Korea

Tel: +82-62-220-6296, Fax: +82-62-228-1330, E-mail: p1052ccy@hanmail.net

(cc) This is an Open Access article distributed under the terms of the Creative Commons Attribution Non-Commercial License (http://creativecommons.org/ licenses/by-nc/3.0) which permits unrestricted non-commercial use, distribution, and reproduction in any medium, provided the original work is properly cited. duodenostomy, BII with and without the Braun procedure, and RY esophagojejunostomy. Presently, ERCP for post-gastrectomy patients is carried out with various devices including a single-balloon enteroscope, double-balloon enteroscope, spiral enteroscope, and cap-fitted endoscope. ${ }^{4-7}$

\section{TYPES OF GASTRECTOMY}

\section{Billroth I gastrectomy}

The Billroth I gastrectomy involves a distal gastrectomy with an anastomosis of the gastric remainder to the duodenum. ${ }^{8}$ The duodenum is straightened, and the major and minor papillae become closer to the stomach due to loss of the superior duodenal angle. Performing ERCP for patients with the Billroth I gastrectomy is nearly as similar as for patients with unaltered gastrointestinal anatomy.

\section{Billroth II gastrectomy}

The BII gastrectomy is one of the most common procedures for surgical treatment of duodenal ulcers and gastric cancer. ${ }^{10}$ The distal stomach is resected and the proximal stomach is anastomosed to the proximal jejunum in an end-to-side arrangement. ${ }^{9}$ To divert the bile away from the remainder of the stomach, a side-to-side jejunojejunostomy between the affer- 
ent and efferent limbs is sometimes created. This procedure is well known as the Braun procedure. ${ }^{11}$

\section{Subtotal/total gastrectomy or gastric bypass with Roux-en-Y anastomosis}

All kinds of RY anastomoses to the esophagus or proximal stomach pose a difficulty when performing ERCP. ${ }^{9} \mathrm{RY}$ reconstructions can be divided into short-limb $(<50 \mathrm{~cm})$ and long$\operatorname{limb}(>100 \mathrm{~cm}) \mathrm{RY}$. The length of a short-limb RY is typically less than $40 \mathrm{~cm}$ from the esophagojejunal or gastrojejunal anastomosis to the jejunojejunal anastomosis at the base of the Y. However, the length of a long-limb RY is longer than $100 \mathrm{~cm}$. Long-limb RY reconstructions are often performed in revisional bariatric operations for patients with inadequate weight loss or as a primary procedure for very obese patients. ${ }^{9}$ The types of gastrectomy are summarized in Table 1.

\section{DEVICE-ASSISTED ERCP}

Nowadays, ERCP for post-gastrectomy patients is carried out with various devices. ${ }^{4.7}$ Recent data have shown that device-assisted ERCP (D-ERCP) allows for high success rates in these patients. ${ }^{4.7}$ When performing a D-ERCP, it is necessary

Table 1. Types of Gastrectomy

\begin{tabular}{|c|c|}
\hline Gastrectomy & $\begin{array}{l}\text { Biliary and pan- } \\
\text { creatic drainage }\end{array}$ \\
\hline Billroth & Intact papilla \\
\hline \multicolumn{2}{|l|}{ Billroth I gastroduodenostomy } \\
\hline \multicolumn{2}{|l|}{$\begin{array}{l}\text { BII gastrojejunostomy (with or without } \\
\text { Braun anastomosis) }\end{array}$} \\
\hline RY anastomosis & Intact papilla \\
\hline \multicolumn{2}{|l|}{$\begin{array}{l}\text { Short-limb subtotal/total gastrectomy } \\
\text { with RY }(<50 \mathrm{~cm})\end{array}$} \\
\hline Long-Limb RY gastric bypass $(>100 \mathrm{~cm})$ & \\
\hline
\end{tabular}

BII, Billroth II; RY, Roux-en-Y. to be thoroughly familiar with the features of the endoscope and accessories that are going to be used. A standard balloon enteroscope has a 200-cm long and 2.8-mm diameter channel. However, the recently developed short single-balloon enteroscope has a $152-\mathrm{cm}$ long and 3.2-mm diameter channel, which allows for all kinds of regular ERCP accessories. ${ }^{12,13}$ The differences between the endoscopes used for D-ERCP are summarized in Table 2. The basic technique for using single- and double-balloon enteroscopes comprises pushing the enteroscope into the deep intestine, pushing the overtube along with the enteroscope until they reach the deep intestine, inflating the balloon(s), fixing the distal end of the overtube in the deep intestine, and pulling the overtube and enteroscope to shorten the intestine. ${ }^{14}$ The basic technique of spiral enteroscopy is different from that of balloon enteroscopy. In spiral enteroscopy, the overtube and enteroscope are advanced as one unit, with a gentle push and rotation until they are past the ligament of Treitz. ${ }^{15}$ The spiral enteroscope overtube is then advanced into the small intestine, with clockwise rotation, and the small bowel is pleated onto the enteroscope and overtube. ${ }^{15}$ For the cap-fitted endoscope, a transparent cap (distal attachment; Olympus, Tokyo, Japan) is attached to the tip of the standard forward-viewing gastroscope or colonoscope. ${ }^{16}$ The cap is very effective for overcoming major difficulties in intubation, cannulation, and ampullary intervention in post-gastrectomy patients. Consecutive comparisons of the different D-ERCP methods may be difficult due to the laborious nature of ERCP procedures in post-gastrectomy patients. Preliminary data and some prospective studies suggest that the different device-assisted enteroscopy methods perform equally. ${ }^{17}$

\section{TECHNICAL KEY POINTS}

\section{Intubation to the ampulla of Vater}

D-ERCP is performed under conscious/deep sedation or general anesthesia because the procedure is laborious. ${ }^{17} \mathrm{Car}-$ bon dioxide $\left(\mathrm{CO}_{2}\right)$ insufflations may help relieve patients' dis-

Table 2. Differences between the Endoscopes for Device-Assisted ERCP

\begin{tabular}{lccc}
\hline Endoscope & Scope length $(\mathbf{c m})$ & Channel diameter $(\mathbf{m m})$ & Accessories \\
\hline Double-balloon enteroscope & 200 & 2.8 & special $<8.5 \mathrm{~F}$ \\
Single-balloon enteroscope & 200 & 2.8 & special $<8.5 \mathrm{~F}$ \\
Short double-balloon enteroscope & 152 & 2.8 & special $<8.5 \mathrm{~F}$ \\
Short single-balloon enteroscope & 152 & 3.2 & regular \\
Spiral enteroscope & 200 & 2.8 & special $<8.5 \mathrm{~F}$ \\
Gastroscope & $103-110$ & $2.0-3.8$ & special or regular \\
Colonoscope & $133-168$ & $3.2-3.7$ & regular \\
\hline
\end{tabular}

ERCP, endoscopic retrograde cholangiopancreatography. 
comfort because the degree of intestinal stretching and distension may be decreased. ${ }^{18,19}$ To reach the ampulla of Vater, the first challenge is documenting the afferent loop. To identify the afferent loop, an intraluminal injection of indigocarmine is valuable. ${ }^{20}$ However, this method is occasionally confusing because the indigocarmine can flow in two or more directions from the lumen at the same time. Instead of indigocarmine, $\mathrm{CO}_{2}$ inflation can be used intentionally as a marker for fluoroscopic guidance. If the lumen is in the correct position, the blind end keeps getting bigger and bigger on fluoroscopy due to $\mathrm{CO}_{2}$ inflation. ${ }^{21}$ When using a cap-fitted forward-viewing endoscope, it is relatively easy to identify the correct course for the loop and to intubate the ampulla of Vater because of some benefits with the cap. First, the cap is essential for an adequate visual field that can show the nature of any angulations encountered because it can provide an adequate distance between the tip of the endoscope and the mucosal folds. In addition, the cap can displace any mucosal folds that obscure the lumen. Therefore, the cap is very useful for overcoming the sharp angulations and searching the opening of the ampulla of Vater. ${ }^{7,16}$ Finally, applying abdominal compression as needed can help in intubating the scope..$^{22}$ In summary, for successful intubation to the ampulla of Vater in post-gastrectomy patients, (1) the use of indigocarmine and carbon dioxide, (2) fluoroscopic guidance, (3) a transparent cap, and (4) manual abdominal compression are essential prerequisites.

\section{Selective cannulation}

Selective cannulation is usually attempted by matching the orientations of the position where the catheter emerges on the endoscopic viewing and the position of Vater's papilla. ${ }^{23}$ Therefore, the position of the working channel is important in terms of the endoscopic view. The positions of the working channels for each of the endoscopes are different: single-balloon enteroscope, 8 oclock position; double-balloon enteroscope, 7 oclock position; pediatric colonoscope, 6 oclock position; and oblique-viewing endoscope, 12 óclock position. ${ }^{23}$ Using a cap-fitted endoscope, selective cannulation is achieved with a push or suction technique, using a straight catheter (PR-10Q; Olympus, Tokyo, Japan) through the cap. Initially, selective cannulation is performed with a push technique; the duodenal base of the papilla is pushed with the 11-oclock margin of the cap, and the tip of the catheter is slowly pushed into the common bile duct (CBD) at the 5 oclock position. If the push technique fails, the suction technique can be useful for selective cannulation; the tip of the catheter is passively advanced into the $\mathrm{CBD}$ while the papilla is being suctioned through the cap. If both the push and suction techniques fail, precutting or a fistulotomy can be attempted. ${ }^{7}$ Precutting or a fistulotomy can be performed after prophylactic pancreatic stent placement to reduce the risk of post-ERCP pancreatitis. If it is difficult to place the prophylactic pancreatic stent, fistulotomy can be more beneficial.

\section{Ampullary intervention}

Ampullary interventions for the treatment of pancreatobiliary diseases include endoscopic sphincterotomy (EST), endoscopic papillary balloon dilation (EPBD), endoscopic papillary large balloon dilation (EPLBD), and self-expandable metal stent (SEMS) insertion. EST is one of the standard techniques for treating bile duct stones in post-gastrectomy patients. EST is usually performed with a push-type sphincterotome or a wire-guided needle knife in post-gastrectomy patients because of inverted anatomy of the ampulla of Vater. ${ }^{24}$ After placing a biliary stent, making an incision with a needle knife over the stent is also a useful technique. ${ }^{25}$ In post-gastrectomy patients, it is often difficult to perform EST because of the restricted scope maneuverability, inverted direction of the sphincterotome, and limited endoscopic view of Vater's papilla. However, EPBD in post-gastrectomy patients is relatively easy to perform and is not associated with an increased need for mechanical lithotripsy or a longer procedure time. ${ }^{26}$ EST combined with EPLBD has been widely used for large bile duct stone removal. ${ }^{27}$ By performing EPLBD after limited EST, the biliary opening is enlarged to a greater extent to allow for removal of large bile duct stones, thus reducing the need for mechanical lithotripsy. Therefore, EPLBD can be used as an effective treatment option for removing large bile duct stones in post-gastrectomy patients. ${ }^{28}$ Finally, transpapillary SEMS can facilitate stone removal in patients with small bile ducts. This technique has appeared to be effective without major complications. ${ }^{29}$ A short-type single-balloon enteroscope can be useful for placing various SEMSs in these patients, with satisfactory outcomes. ${ }^{30}$ SEMSs can be a good option for ampullary interventions that carry a low risk of major complications in post-gastrectomy patients.

\section{CONCLUSIONS}

D-ERCP should be considered as the first-step approach for ERCP in post-gastrectomy patients. For successful ERCP, good knowledge of postoperative anatomy and various devices, including endoscopes and accessories, are mandatory before performing ERCP procedures for post-gastrectomy patients.

\section{Conflicts of Interest}

The author has no financial conflicts of interest. 


\section{REFERENCES}

1. Cotton PB. ERCP. Gut 1977;18:316-341.

2. Moreels TG. Endoscopic retrograde cholangiopancreatography in patients with altered anatomy: How to deal with the challenges? World J Gastrointest Endosc 2014;6:345-351.

3. Lee A, Shah JN. Endoscopic approach to the bile duct in the patient with surgically altered anatomy. Gastrointest Endosc Clin N Am 2013;23:483-504.

4. Itoi T, Ishii K, Sofuni A, et al. Single-balloon enteroscopy-assisted ERCP in patients with Billroth II gastrectomy or Roux-en-Y anastomosis (with video). Am J Gastroenterol 2010;105:93-99.

5. Chu YC, Yang CC, Yeh YH, Chen CH, Yueh SK. Double-balloon enteroscopy application in biliary tract disease-its therapeutic and diagnostic functions. Gastrointest Endosc 2008;68:585-591.

6. Kogure H, Watabe H, Yamada A, et al. Spiral enteroscopy for therapeutic ERCP in patients with surgically altered anatomy: actual technique and review of the literature. J Hepatobiliary Pancreat Sci 2011;18:375379.

7. Ki HS, Park $\mathrm{CH}$, Jun $\mathrm{CH}$, et al. Feasibility of cap-assisted endoscopic retrograde cholangiopancreatography in patients with altered gastrointestinal anatomy. Gut Liver 2015;9:109-112.

8. Tavakkolizadeh A, Ashley SW. Operations for peptic ulcer. In: Yeo CJ, ed. Shackelford's surgery of the alimentary tract. 7th ed. Philadelphia (PA): Elsevier Saunders; 2013. p. 701-719.

9. Gómez V, Petersen BT. Endoscopic Retrograde Cholangiopancreatography in Surgically Altered Anatomy. Gastrointest Endosc Clin N Am 2015;25:631-656.

10. Evers BM. Gastric resection: Billroth II. In: Townsend CM Jr, Evers BM, eds. Atlas of general surgical techniques. 1st ed. Philadelphia (PA): Elsevier Saunders; 2010. p. 292-303.

11. Olbe L, Becker HD. Partial gastrectomy with Billroth II resection and alternative methods. In: Becker HD, ed. Surgery of the Stomach. Berlin: Springer-Verlag; 1988. p. 50-70.

12. Shimatani M, Takaoka M, Ikeura T, Mitsuyama T, Okazaki K. Evaluation of endoscopic retrograde cholangiopancreatography using a newly developed short-type single-balloon endoscope in patients with altered gastrointestinal anatomy. Dig Endosc 2014;26 Suppl 2:147-155.

13. Kawamura T, Uno K, Suzuki A, et al. Clinical usefulness of a short-type, prototype single-balloon enteroscope for endoscopic retrograde cholangiopancreatography in patients with altered gastrointestinal anatomy: preliminary experiences. Dig Endosc 2015;27:82-86.

14. May A, Nachbar L, Wardak A, Yamamoto H, Ell C. Double-balloon enteroscopy: preliminary experience in patients with obscure gastrointestinal bleeding or chronic abdominal pain. Endoscopy 2003;35:985-991.

15. Akerman PA, Agrawal D, Cantero D, Pangtay J. Spiral enteroscopy with the new DSB overtube: a novel technique for deep peroral small-bowel intubation. Endoscopy 2008;40:974-978.

16. Park CH, Lee WS, Joo YE, Kim HS, Choi SK, Rew JS. Cap-assisted
ERCP in patients with a Billroth II gastrectomy. Gastrointest Endosc 2007;66:612-615.

17. Moreels TG. Altered anatomy: enteroscopy and ERCP procedure. Best Pract Res Clin Gastroenterol 2012;26:347-357.

18. Bretthauer M, Seip B, Aasen S, Kordal M, Hoff G, Aabakken L. Carbon dioxide insufflation for more comfortable endoscopic retrograde cholangiopancreatography: a randomized, controlled, double-blind trial. Endoscopy 2007;39:58-64.

19. Hirai F, Beppu T, Nishimura T, et al. Carbon dioxide insufflation compared with air insufflation in double-balloon enteroscopy: a prospective, randomized, double-blind trial. Gastrointest Endosc 2011;73:743-749.

20. Yano $T$, Hatanaka $H$, Yamamoto $H$, et al. Intraluminal injection of indigo carmine facilitates identification of the afferent limb during double-balloon ERCP. Endoscopy 2012;44 Suppl 2 UCTN:E340-E341.

21. Iwai T, Kida M, Yamauchi H, Imaizumi H, Koizumi W. Short-type and conventional single-balloon enteroscopes for endoscopic retrograde cholangiopancreatography in patients with surgically altered anatomy: single-center experience. Dig Endosc 2014;26 Suppl 2:156-163.

22. Yamauchi $\mathrm{H}$, Kida $\mathrm{M}$, Imaizumi $\mathrm{H}$, et al. Innovations and techniques for balloon-enteroscope-assisted endoscopic retrograde cholangiopancreatography in patients with altered gastrointestinal anatomy. World J Gastroenterol 2015;21:6460-6469.

23. Okabe Y, Ishida Y, Kuraoka K, Ushijima T, Tsuruta O. Endoscopic bile duct and/or pancreatic duct cannulation technique for patients with surgically altered gastrointestinal anatomy. Dig Endosc 2014;26 Suppl 2:122-126.

24. Ito K, Masu K, Kanno Y, Ohira T, Noda Y. Ampullary intervention for bile duct stones in patients with surgically altered anatomy. Dig Endosc 2014;26 Suppl 2:116-121.

25. Ryozawa S, Iwamoto S, Iwano H, Ishigaki N, Taba K, Sakaida I. ERCP using double-balloon endoscopes in patients with Roux-en-Y anastomosis. J Hepatobiliary Pancreat Surg 2009;16:613-617.

26. Bergman JJ, van Berkel AM, Bruno MJ, et al. A randomized trial of endoscopic balloon dilation and endoscopic sphincterotomy for removal of bile duct stones in patients with a prior Billroth II gastrectomy. Gastrointest Endosc 2001;53:19-26.

27. Ersoz G, Tekesin O, Ozutemiz AO, Gunsar F. Biliary sphincterotomy plus dilation with a large balloon for bile duct stones that are difficult to extract. Gastrointest Endosc 2003;57:156-159.

28. Choi CW, Choi JS, Kang DH, et al. Endoscopic papillary large balloon dilation in Billroth II gastrectomy patients with bile duct stones. J Gastroenterol Hepatol 2012;27:256-260.

29. Jun $\mathrm{CH}$, Park $\mathrm{CH}$, Jeon J, et al. Feasibility of self-expandable metal stents for preservation of sphincter of Oddi function in patients with common bile duct stones: a pilot study. Gastrointest Endosc 2015;82:719-723.

30. Yamauchi H, Kida M, Okuwaki K, et al. A Case Series: Outcomes of Endoscopic Biliary Self-Expandable Metal Stent for Malignant Biliary Obstruction with Surgically Altered Anatomy. Dig Dis Sci 2016;61:24362441. 